\title{
Detection of Smoldering Fire in Electrical Equipment with High Internal Air Flow
}

\author{
HIROBUMI HOTTA and SATORU HORIUCHI \\ Nohmi Bosai Kogyo Co., Ltd. \\ 4-7-3, Kudan-Minami, Ciyoda-ku, Tokyo 102, Japan
}

\section{ABSTRACT}

A series of fire tests of smoke detectors was conducted with a view to seeking a method for early detection of electrical component failures, e.g. smoldering of printed circuit boards and cables, burst of capacitor, in highly integrated (using LSI's) electrical equipment as represented by electronic computers. As a result, it has been found that, in equipment where there is high air flow for cooling, the ionization detector shows better response compared with the photoelectric detector if the air velocity exceeds about $1 \mathrm{~m} / \mathrm{s}$. It has been a general practice to avoid installation of the ionization detector in a place where it is subjected to high air flow because the output level changes due to air flow characteristics. However, a small ionization detector which is intended for use in equipment such as computer and which is stable against air flow has been developed. This paper describes this newly developed detector as we11.

\section{INTRODUCTION}

As proved by introduction of computers with capacities of $64 \mathrm{~KB}, 256 \mathrm{~KB}$ and IMB-RAM on the market, development of computers is being directed toward higher integration using VLSI's and speeding up. As a result of this, there is a greater danger that a large amount of heat is generated in limited spaces, thus it has become one of the important questions to adopt adequate measures (cooling) against heat as we11 as fire retardation of electronic components. In general, electronic components are provided with radiative fins for air cooling to maintain the equipment below a predetermined temperature. In some types of equipment, air velocity exceeds $10 \mathrm{~m} / \mathrm{s}$.

However, there are such cases where printed circuit boards and cables burn due to defective components, overload etc. Although some equipment is provided with heat detectors for detection of such fires, it is difficult to detect them at the smoldering stage. A possible alternative is the smoke detector. As smoke detectors, the ionization detector and light scattering detector are known. Characteristics of those detectors are described in detail in papers ${ }^{1,2}$ by T.G.K. Lee, R.W. Bukowski, and G.W. Mulholland. It is generally known from their characteristics that the former is highly sensitive to flaming fire like open wood fire, and the latter is highly sensitive to smoldexing fire of PVC insulated cables and beds. However, according to the above paper, there is a difference in the smoke particle size distribution between the cases where a punk is burning in still air and in moving air as shown in FIGURE 1, and there- 


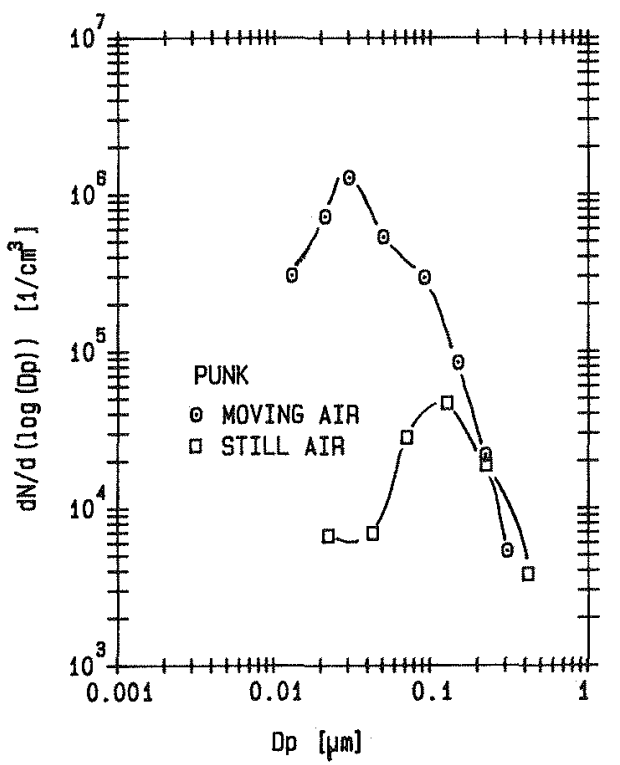

FIGURE 1 Effect of air movement $(2 \mathrm{~m} / \mathrm{s})$ on particle size

fore the light scattering detector may not always have a good response to smoldering fires. Besides, punk sticks continue self-combustion and especially tend to keep glowing if air is supplied. Since electronic components such as printed circuit boards and cables, discussed in this paper are flame retardant and hardly burn unless electric power is continuously supplied at the initial stage of combustion, their burning characteristics are different from that of the punk stick. Therefore, this paper describes experiments which were carried out with a view to studying combustion of electrical components especially printed circuit boards, cables, and capacitors in equipment with internal flow of cooling air, and the sensor to detect fires from these components.

In this paper, "detector" and "sensor" are distinguished in that a "detector" sends out discrete ON-OFF output and a "sensor" sends out analog output.

\section{TEST METHOD}

The apparatus used for the tests was a smoke tunnel with an open path of 7. Om long to obtain conditions close to those of electrical equipment with air cooling fans. FIGURE 2 shows the tunnel structure. Air velocity in the tunnel was controlled by using two fans: one for freely changing the air velocity at the fire point, and the other for setting the air velocity at the measuring point constant regardless of the air velocity at the fire point. A constant air velocity was set within a range 0.5 to $8 \mathrm{~m} / \mathrm{s}$ by means of voltage regulators according to the indication given by hot wire anemometers provided at each measuring point. The reasons why air velocity at the sensors' location was kept constant were to reduce the dilution effect by air flow and to maintain the normal level and response of the sensors constant. 
For heating up the electrical components to smolder, a $3 \mathrm{KW}$ hot plate (300mm in diameter, $200 \mathrm{~V}$ AC) was used. Temperature control was made by voltage regulator with reference to the reading of type $\mathrm{K}$ thermocouple (elemental wire AWG \#30). However, combustion of capacitors was initiated by applying a voltage exceeding the breakdown voltage of each capacitor. Smoke densities were measured by means of analog output type ionization sensor (type FDS 221) and a light scattering sensor (type FDK 224) manufactured by Nohmi Bosai Kogyo Co., Ltd. At the same time, the smoke densities were also measured by two kinds of smoke densitometers having a light path length of $28 \mathrm{~cm}$. One of them is the same type as that used for the approval testing of smoke detectors in Japan and has a sensitivity range within the visible region (typical wavelength of $570 \mathrm{~nm}$ ) and almost the same characteristics as the densitometer used for the test prescribed in UL-268 ${ }^{3}$. The other is sensitive in the near-infraredregion (typical wavelength 950nm) conforming to the standard prescribed in EN54 Part 74 . The following are three types of electrical components subjected to the tests and their combustion conditions.

(i) Printed Circuit Board $20 \times 20 \times 1.6 \mathrm{~mm}$ Fiber-reinforced epoxide

(ii) Cable PVC insulated flat cable used for computer wiring

(iii) Aluminum electrolytic capacitor Withstand voltage $16 \mathrm{~V}$, Capacity $2200 \mu \mathrm{F}$
Combustion in the range 300 to $500^{\circ} \mathrm{C}$ on the hot plate. Typical temperature $450^{\circ} \mathrm{C}$.

Combustion in the range 300 to $450^{\circ} \mathrm{C}$ on the hot plate. Typical temperature $350^{\circ} \mathrm{C}$.

Breakdown at an applied voltage of $16 \mathrm{~V} \mathrm{AC}$ or $35 \mathrm{~V} \mathrm{DC}$.

\section{Top View}
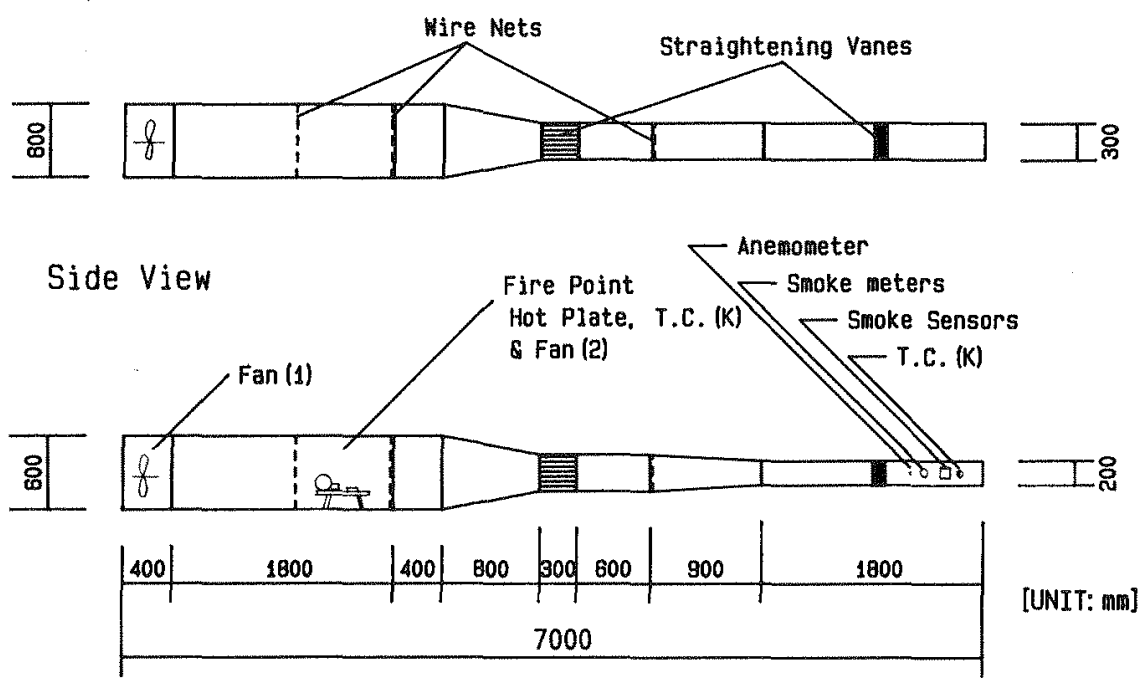

FIGURE 2 Smoke test tunnel 

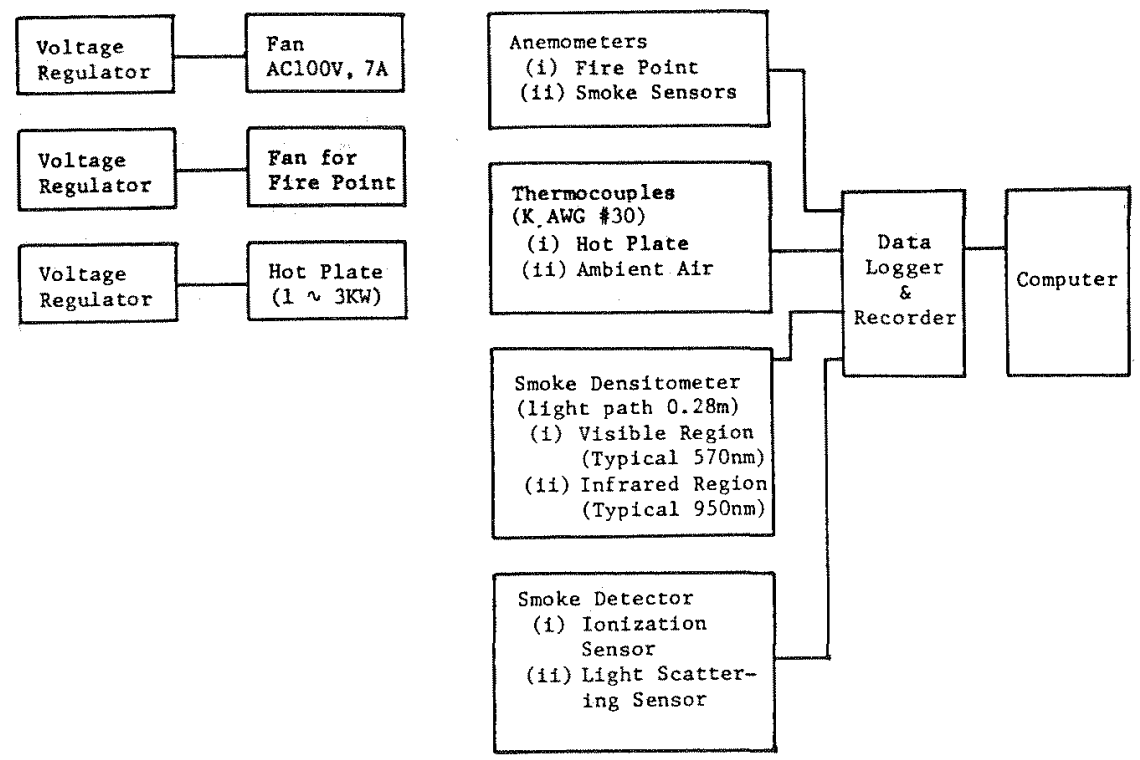

FIGURE 3 Block diagram

\section{SENSOR CALIBRATION}

The ionization sensor and light scattering sensor were calibrated in accordance with Japanese technical standards ${ }^{6}$ for fire alarm systems. The test chamber used for this caltbration is a smoke circulating box. Smoke for the calibration was generated by smoldering of a sheet of filter paper which was sandwiched between two hot plates of $75 \mathrm{~mm}$ diameter and heated up to $400^{\circ} \mathrm{C}$. The circulating air velocity was $0.2 \mathrm{~m} / \mathrm{s}$.

The ionization sensor is calibrated with a parallel electrode measuring ionization chamber and the density is indicated by the rate of ionization current change $(x=($ Io-I $) /$ Io $)$. FIGURE 4 indicates the correlation between MIC prescribed in EN54 Part 7 and Japanese MTC including the scale of $Y$ value as well as $x$ Value 5,7 . The standard sensitivity of the fonization detector in Japan is $x=0.24$ and the corresponding value in EN-MIC is about 1.2 in $Y$ value. The value obtained with the ionization sensor in the test is expressed in $\mathrm{Y}$ value, which is obtained by calibrating the sensor output with this calibration value.

The smoke densitometer for calibrating the light scattering sensor is an extinction type densitometer sensitive in the visible region. It uses an incandescent lamp with a color temperature of $2800 \mathrm{~K}$ for light source and a luminosity -corrected selenium photo-cell with a typical wavelength of $570 \mathrm{~nm}$ for the light receiving element. The standard light scattering detector used in Japan has a sensitivity of $10 \% / \mathrm{m}$ in extinction rate. The corresponding $\mathrm{m}$ value defined in EN 54 Part 7 is $0.46(\mathrm{~dB} / \mathrm{m})$. In the test results for the light scattering sensor, the value indicated represents the sensor output for filter paper smoke and converted into $\mathrm{m}(\mathrm{dB} / \mathrm{m})$ value. Here, it should be noted that the selenium photo -cell differs in light sensitive region from the densitometer used in EN standards and that the light scattering sensor used has a light emitting cycle of 0.2 second which is 20 times shorter than that for ordinary detectors. 


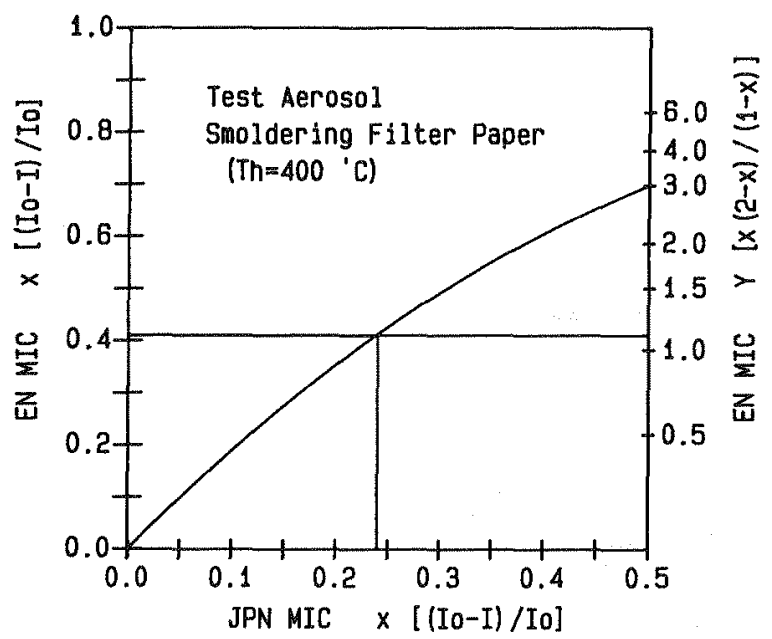

FIGURE 4 Correlation between EN-MIC and Japanese-MIC

["MIC": Measuring Ionization Chamber]

\section{TTEST RESULTS AND CONSTDERATTON}

FIGURE 5 shows typical results obtained with the ionization and light scattering sensors in smoldering fire of a printed circuit board. The conditions under which these data were taken are as follows.

- Amount of combustion: Glass-fiber reinforced epoxide printed circuit boards

3 sheets (initial weight $3.6 \mathrm{~g}$ )

- Hot plate cemperature: $450^{\circ} \mathrm{C}$

- Duration of combustion: 3 minutes

- Air velocity at $1 \mathrm{~m} / \mathrm{s}$ (constant) location of sensor:

- Air velocity at fire 0.5 to $8 \mathrm{~m} / \mathrm{s}$ point:

The result shows that ionization sensor output increases and light scattering sensor output decreases with increasing air velocity at the fire point. This result also indicates a decrease of smoke particle size and increase of particle concentration $(z)$. To prove this, the extinction type smoke densities ... m values $(\mathrm{dB} / \mathrm{m})$ both in the visible region and near-infrared region are compared in FIGURE 6. The ratio of $\mathrm{m}$ values obtained in 0.8 for an air velocity at the fire point of $0.5 \mathrm{~m} / \mathrm{s}$, but falls to 0.35 for an air velocity of $4.0 \mathrm{~m} / \mathrm{s}$. FIGURE 7 shows the comparison of response of the ionization sensor with that of the light scattering sensor, and includes results obtained by changing quantities of the samples in such a way that they show weight loss of $0.2 \mathrm{~g}, 0.4 \mathrm{~g}$, and $0.6 \mathrm{~g}$ during three minutes" combustion under five different air velocities, from $0.5 \mathrm{~m} / \mathrm{s}$ to $8 \mathrm{~m} / \mathrm{s}$ at the fire point. The plotted data show the maximum values of 


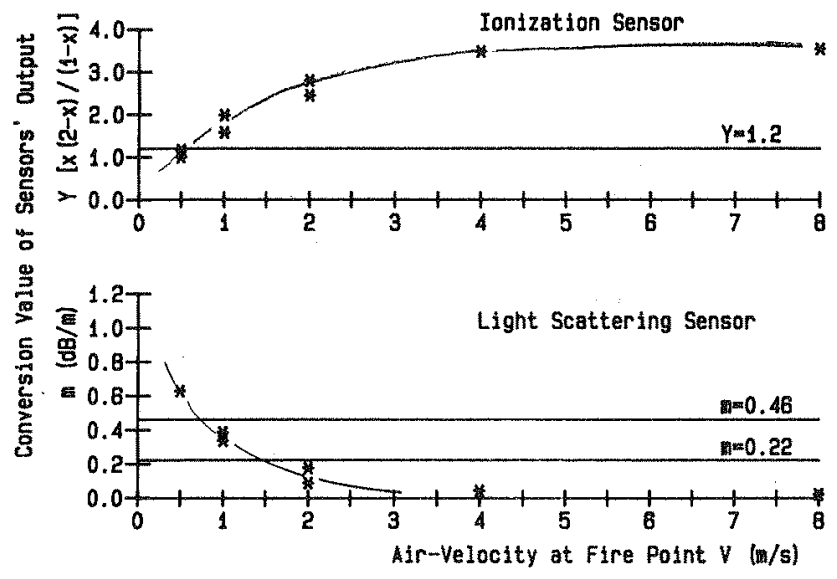

FIGURE 5 Correlation between air velocity at fire poing and output of smoke sensor

Burning material: printed circuit board

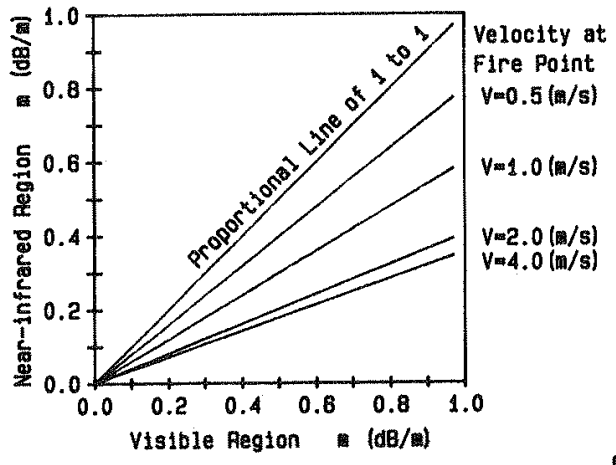

FIGURE 6 Correlation between smoke densities in visible region and near infrared region with air velocity at fire point

Burning materia1: printed circuit board

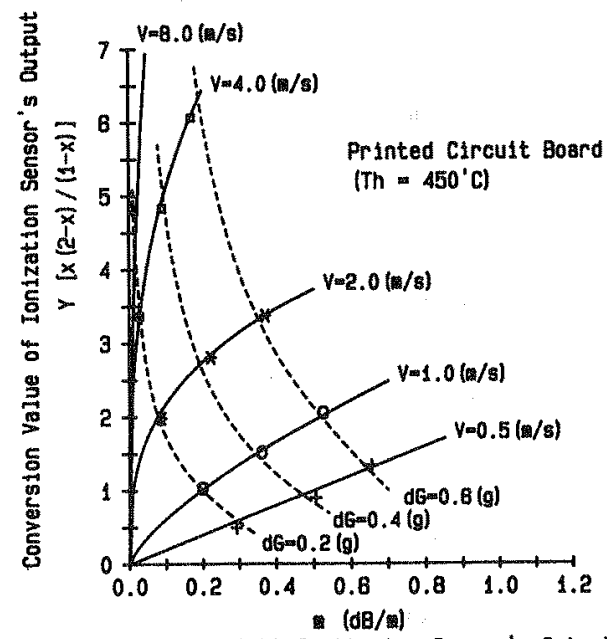

Conversion value of Light Scattering Sensor's Output

FIGURE 7 Comparison of response of the Ionization sensor with that of the light scattering sensor 
the sensor outputs in each test. The broken lines show the curves at the reduction of the corresponding weight and solid lines are isolines of air velocity. For a velocity of $0.5 \mathrm{~m} / \mathrm{s}$, the relationship between $\mathrm{m}$ and $\mathrm{X}$ values is approximately linear but as the velocity increases, the solid lines become more apart from the straight line forming curves. This suggests coagulation in a shorter time or increase of particle size following increase of the smoke generation rate.

FIGURE $8 \mathrm{a}$ shows the rate of weight loss versus air flow during 3 minutes required for operation of the ionization detector with threshold level. $Y=1.2$ and the light scattering detector with threshold level $m=0.22$ and $m=0.46$. While the weight loss increased with increase of air velocity at fire point, in the case of operation of the light scattering detector, there was decrease in the weight loss in the case of the Ionzation detector. This indicates that the ionization detector has higher sensitivity. Although the air velocity at the sensors' location was kept constant, it practically increased with increase of air velocity at the fire point. Therefore, dilution by air flow must be taken into consideration. If the particle diameter is constant, the weight loss at the time of operation of detector is the function of air flow rate. FIGURE 8b shows the rate of weight loss with consideration of dilution. It shows that the sensitivity of the ionization detector is almost constant, but that of the light scattering detector is extremely decreased. It is varied by the setting level of the threshold of the detector, but the turnning piont is 0.5 to $1.0 \mathrm{~m} / \mathrm{s}$.
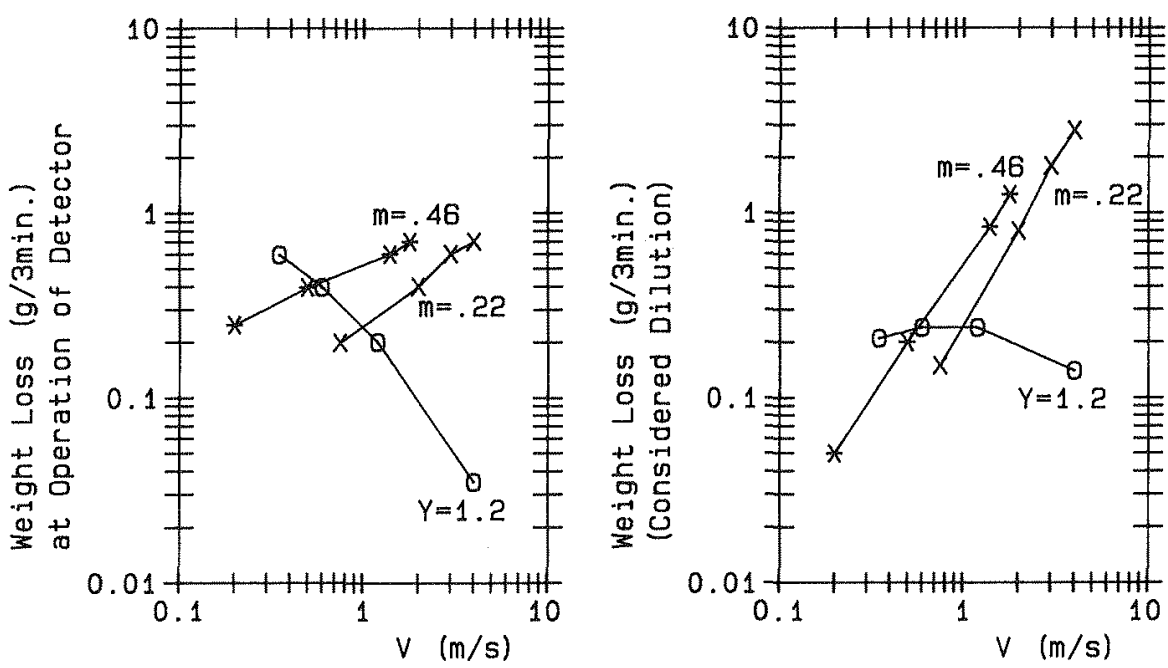

FIGURES $8 \mathrm{a}(1 \mathrm{eft}), 8 \mathrm{~b}$ (right) Weight loss required for operation of the smoke detector 

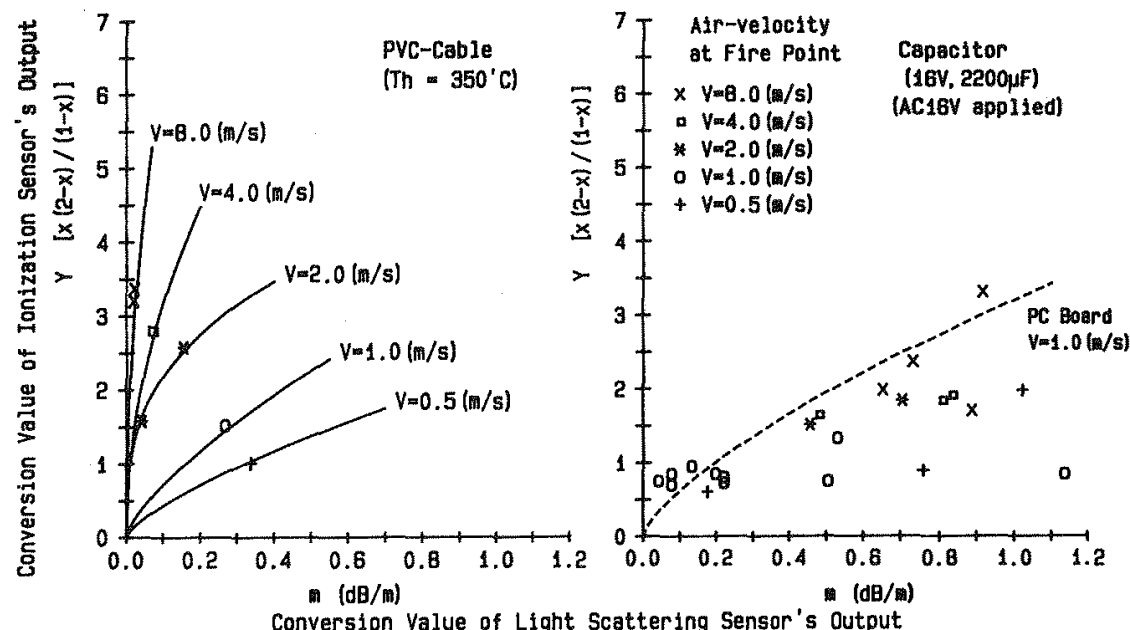

FIGURES 9 (left), 10 (right) Comparison of response of the ionization sensor with that of the light scattering sensor

FIGURE 9 shows data for smoldering of a PVC insulated cable at $350^{\circ} \mathrm{C}$, indicating a trend similar to the example for the printed circuit board. This indicates that when commercially available fonization detectors and light scattering detectors are compared, the former show better response to smoldering fire in the printed circuit board and PVC insulated cable, if the air velocity at the location of the fire exceeds $1 \mathrm{~m} / \mathrm{s}$. FTGURE 10 shows data obtained from combustion of a capacitor, which was caused by application of a voltage exceeding its breakdown voltage in air flow. In these data we see no significant trend by air velocities at the fire point. Possibly, this is because smoke grows within the capacitor, and almost stabilized smoke is discharged out of the capacitor. Therefore, it shows the same trend as smoldering fire in the printed circuit board at low air velocities, and it can be said that the light scattering sensor shows better response. However, attention must be paid to the fact thet the light scattering sensor enits light in pulses to prevent misoperation due to background noise from external 1ight, and with consideration of reduction of power consumption, LED life, etc. Therefore, the light scattering sensor may fail to detect transient smoke from a capacitor in a high air velocity.

\section{DEVELOPMENT OF IONIZATION SENSOR HOUSED IN ELECTRICAL EQUIPMENT}

As described in the preceding paragraph, the ionization detector is suitable for early detection of fire in electrical equipment in which there is a flow of cooling air. An ionization sensor newly developed for use within such equipment is shown below. FIGURE 11 shows an external view of this compact sensor with dimensions of less than $40 \mathrm{~mm}$ on each side. FIGURE 12 shows the horizontal and vertical air flow characteristics of this sensor, in which the maximum and minimum values are given to show output fluctuation ranges in deviation from the air velocity of $0 \mathrm{~m} / \mathrm{s}$ when angles of the horizontal and vertical air flow are varied. Threshold levels in the figure are standard values, the outputs at each air velocity of $10 \mathrm{~m} / \mathrm{s}$ being $+20 \%$ or less of these values. This sensor has less possibility of false operation of delayed detection which is caused by influence of air flow and which is inherent in the conventional ionization detector. The 

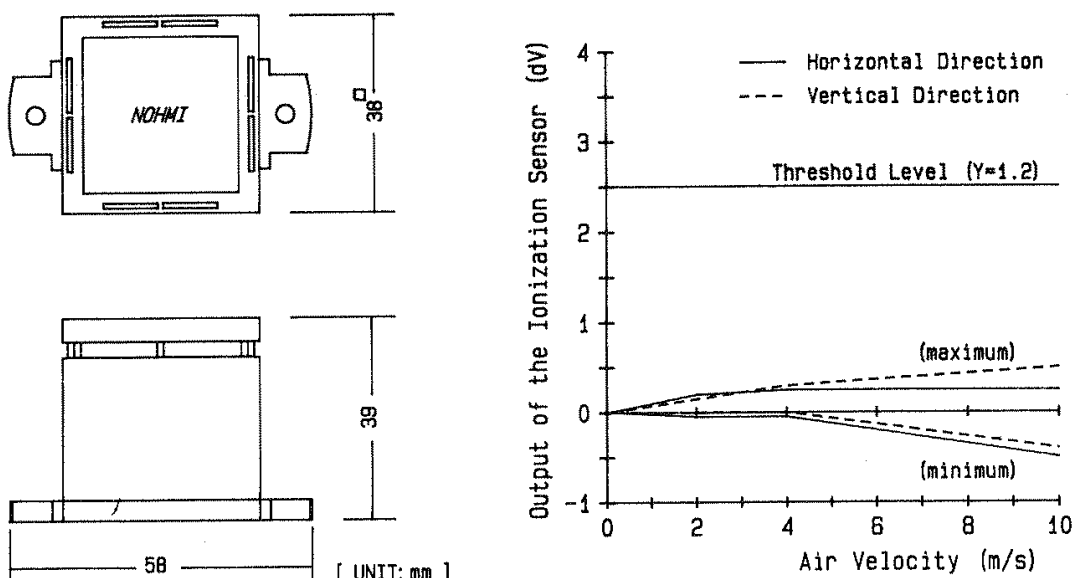

FTGURE 11 Ionization sensor (FDS765C)

FIGURE 12 Air flow characteristics of the ionization sensor

response time to smoke in air flow exceeding $1 \mathrm{~m} / \mathrm{s}$ is within 15 seconds. This analog ionization sensor, connected to a contro1 unit, is capable of monitoring smoke down to low output leve1. It has also been possible to provide the sensor with a trouble detecting function, multistage alarm function, and remote operation test function. Therefore, this sensor is suitable for early detection of equipment fire.

\section{CONCLUSION}

Generally, the ordinary smoke detectors are arranged in such a way that each of them supervises a large area. Therefore, even in the case of a flaming fire to which the ionization detector shows good response, it takes a certain time for smoke to reach the detector if the fire occurs remote from the detector, and thus detection may be delayed due to smoke coagulation.

However, even in the case of smoldering fire which is not favorable to the ionization detector, it has proved to show good response if smoldering fire occurs within the equipment where there is an air flow. It has also been found that the ionization detector shows better response than the light scattering detector to smoldering fire in printed circuit boards and cables, if air velocity exceeds about $1 \mathrm{~m} / \mathrm{s}$. There is an exceptional case in which the 1 ight scattering detector shows better resopnse to smoldering fire in the capacitor, but might fail to give an alarm depending on the light emitting pulse cycle if there is high air flow. Therefore, the ionization detector is preferable for early detection of fire in equipment with a cooling fan. It is expected that the sma11 ionization sensor reported in this paper will demonstrate its ability to detect fire within electrical equipment. 


\section{ACKNOWLEDGEMENT}

The author wishes to thank Professor $T$. Handa for his valuable advice in preparing this paper.

\section{NOMENCLATURE}

$\mathrm{dG}$ weight loss $[\mathrm{g}]$

I ionization current [pA]

Io initial ionization current [pA]

m optical density $[\mathrm{dB} / \mathrm{m}]$

Th surface temperature of hotplate $\left[{ }^{\circ} \mathrm{C}\right]$

$\mathrm{V}$ air velocity [m/s]

$\mathrm{x}$ rate of ionization current change $[(\mathrm{TO}-\mathrm{I}) / \mathrm{Io}]$

$\mathrm{Y} \quad$ smoke concentration $[\mathrm{x}(2-\mathrm{x}) /(1-\mathrm{x})]$

\section{REFERENCE}

1. Lee, T.G.K. and Mulholland, G.W.: "Physical Properties of Smokes Pertinent to Stnoke Detector Technology," NBS, NBSIR 77-1312, 1977.

2. Bukowski, R.W. and Mulholland, G.W.: "Smoke Detector Design and Smoke Properties," NBS, TN973, 1978.

3. "Smoke Detectors for Fire Protective Signaling Systems," Standard for Safety, UL268-1981, Underwriters Laboratories Inc., 1983.

4. "Components of Automatic Fire Detection Systems, Part 7, Specification for Point-type Smoke Detectors using Scattered Light, Transmitted Light or Ionization," EN54-Part 7.

5. "Components of Autonatic Fire Detection Systems, Part 9, Methods of Test of Sensitivity to Fire," EN54-Part 9.

6. Ministerial Ordinance for Technical Standards for Fire Alarm System (Japan)," Minitry of Home Affairs, 1977.

7. Scheidweiler A.; "The Ionization Chamber as Smoke Dependent Resistance," Fire Technology, 2, 12, 1976.

8. Takemoto A. and Watanabe A.: "The Particle Size Distribution Products and Thier Effects on the Response of Smoke Detectors," Report of Fire Research Institute of Japan, 38, 1974.

9. Watanabe A. and Takemoto A.: "Response Characteristics of Smoke Detectors," Bulletin of the Fire Prevention Society of Japan, 2, 21, 1972.

10. Helsper C., Fissan H.J., Muggli J. and Scheidweiler A.: "Particle Number Distributions of Aerosols from Test Fires," J. Aerosol Sci., 11, 1980, (UK). 